\title{
NOTA RADIOLÓGICA
}

\section{Caso Radiológico Pediátrico}

\author{
FERNANDO IÑÍGUEZ O.* y CRISTIÁN GARCÍA B.****
}

\section{HISTORIA CLÍNICA}

Niño de 10 años de edad, proveniente de un medio rural, que consulta por historia de tos y expectoración crónicas, de alrededor de dos años de evolución. Además ha presentado, por lo menos cuatro episodios de neumopatía aguda, confirmados con radiografía $(\mathrm{Rx})$ de tórax, todas ellas tratadas con antibióticos en forma ambulatoria, con buena respuesta clínica. Esto se ha asociado a un moderado retardo del desarrollo pondoestatural. Al examen clínico, destacan roncus y estertores bilaterales abundantes en ambos pulmones. Actualmente estable, sin signos clínicos sugerentes de un proceso pulmonar agudo.

Por los antecedentes, se solicitó una Rx de tórax (Figura 1) y luego una tomografía computarizada (TC) de tórax (Figura 2) .

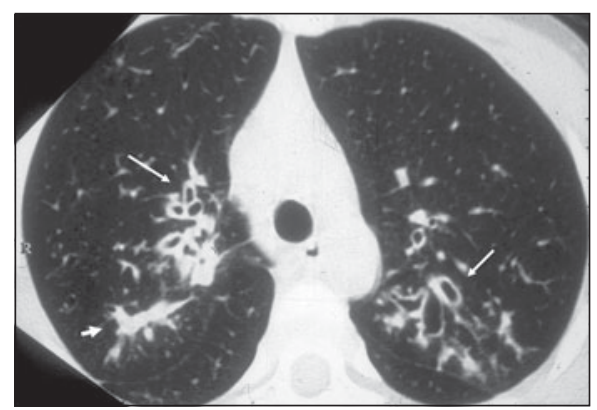

Figura 2a. Tomografía computarizada de tórax.

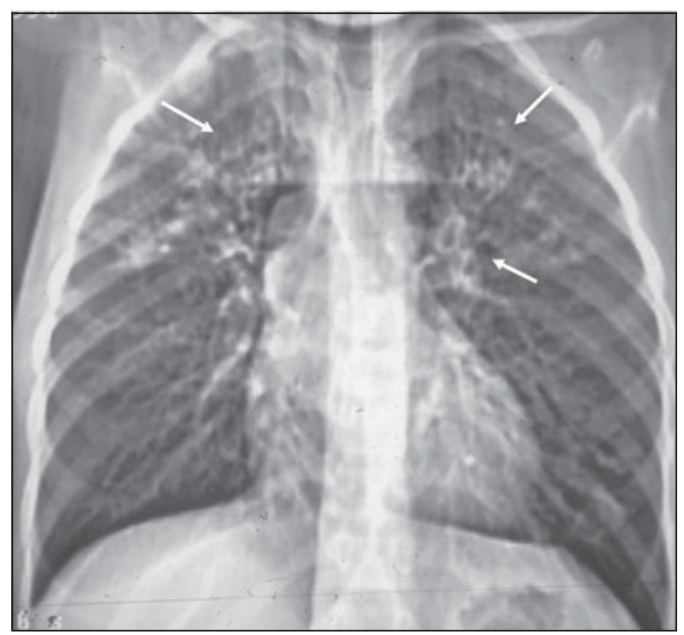

Figura 1. Radiografía de tórax en proyección pósteroanterior.

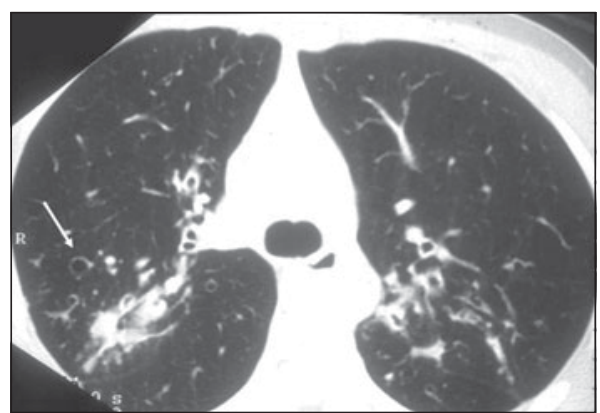

Figura 2c. Tomografía computarizada de tórax.

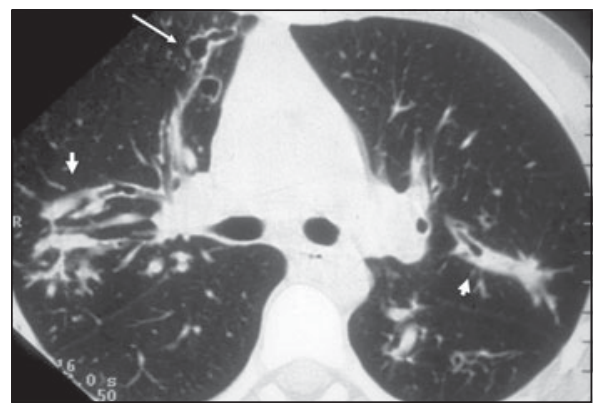

Figura 2b. Tomografía computarizada de tórax.

\section{¿Cuál es su hipótesis diagnóstica?}

\footnotetext{
* Departamento de Pediatría, y ** Departamento de Radiología, Facultad de Medicina. Pontificia Universidad Católica de Chile.
} 


\section{HALLAZGOS RADIOLÓGICOS}

La Figura 1 muestra sombras intersticiales, con engrosamiento del intersticio peribronquial en las regiones centrales de ambos pulmones (flechas). La Figura 2 (a,b,c) muestra bronquiectasias cilíndricas y saculares múltiples en ambos pulmones (flechas), engrosamiento del intersticio peribronquial e impactación mucosa (cabezas de flecha) en forma bilateral.

Con los antecedentes clínicos y los hallazgos radiológicos, debe plantearse como primera posibilidad una fibrosis quística. Dentro del diagnóstico diferencial, habría que considerar disquinesia ciliar e inmunodeficiencia.

El estudio inmunológico resultó normal. El test del sudor fue positivo para fibrosis quística.

\section{DIAGNÓSTICO}

Fibrosis quística.

\section{DISCUSIÓN}

La fibrosis quística (FQ) es una enfermedad autosómica recesiva, más común en los grupos de origen caucásico. Se trata de una condición multisistémica progresiva y letal, cuyo pronóstico depende del adecuado manejo multidisciplinario $^{1}$. Se origina por mutaciones de un gen en el brazo largo del cromosoma 7, que codifica para la proteína reguladora de la conductancia transmembrana de la FQ. Esta proteína posee 1.480 aminoácidos y se ubica en la porción apical de la membrana de las células epiteliales secretoras en hígado, pulmón, senos paranasales, páncreas y aparato reproductivo. Actúa como canal de cloruro, regulado por AMP cíclico, entre otras múltiples funciones de esta mólecula extraordinaria ${ }^{2}$. La mutación más común es la DeltaF508 (deleción de fenilalnina en posición 508) que en Chile representa el 25 a $50 \%$ de los alelos ${ }^{1}$. Se han descrito 5 clases de mutaciones, según el mecanismo de alteración de la proteína reguladora ${ }^{3}$. Las manifestaciones principales de la enfermedad son enfermedad pulmonar obstructiva crónica, insuficiencia pancreática exocrina y elevación de la concentración de electrolitos en el sudor. La presentación clínica es variada según la edad y su diagnóstico requiere un alto índice de sospecha cuando ésta no es la habitual.

Dentro del estudio de los pacientes con FQ, la radiografía $(\mathrm{Rx})$ de tórax ha sido tradicional- mente el método de imágenes empleado para evaluar las alteraciones pulmonares. Permite evaluar la progresión de la enfermedad, pero puede no demostrar cambios significativos en las exacerbaciones agudas, en casos de traqueobronquitis.

Signos de hiperinsuflación, con diafragmas aplanados, aumento de la transparencia retroesternal y aumento del diámetro anteroposterior del tórax, pueden verse en la infancia temprana, pero son generalmente evidentes en niños mayores, aumentan con los años y ocurren como consecuencia de atrapamiento aéreo por obstrucción de la vía aérea fina. Los cambios progresivos incluyen opacidades nodulares o tubulares, por tapones mucosos endobronquiales o impactación mucosa y la presencia de bronquiectasias $^{3,4}$. El rendimiento de la Rx de tórax en el diagnóstico de bronquiectasias es bajo y con mayor frecuencia se sospecha cuando existen sombras focales, generalmente centrales o basales, que persisten en el tiempo, en un paciente con sintomatología prolongada. Con menor frecuencia pueden observarse estructuras tubulares de paredes engrosadas, que corresponden a las bronquiectasias propiamente tales.

La Rx de tórax no evidencia alteraciones significativas en la etapa precoz de la enfermedad. Durante el primer año de de vida, puede no mostrar alteraciones o mostrar hallazgos inespecíficos, generalmente sombras intersticiales hiliares y perihiliares bilaterales, similares a las observadas en infecciones virales, aspiración crónica, etc.

Actualmente, el método más preciso para evaluar los cambios morfológicos en el pulmón producidos por la FQ es la tomografía computarizada (TC) de alta resolución, la que puede mostrar alteraciones tales como bronquiectasias, engrosamiento de la pared bronquial, tapones mucosos, atrapamiento aéreo y destrucción del parénquima pulmonar ${ }^{5}$. La TC puede mostrar alteraciones significativas, sin que éstas sean evidentes en la Rx de tórax. En general, los hallazgos son variables y dependen de la etapa de la enfermedad. Los signos precoces de enfermedad en la TC incluyen un patrón de atenuación en mosaico, nódulos centrolobulillares y apariencia de "árbol en brote", reflejando afectación de la vía aérea fina. El patrón en mosaico se debe a una bronquiolitis obliterante constrictiva regional, con áreas hipoventiladas que también están mal perfundidas por vasoconstricción refleja, lo que produce una disminución en la atenuación de la señal, al comparar con áreas bien perfundidas. Estas diferencias se acentúan 
en las imágenes obtenidas en espiración, donde las zonas de atrapamiento aéreo se hacen más evidentes. La mayor frecuencia del patrón en mosaico en los niños pequeños se explica por la menor distensibilidad de la vía aérea, que tiende a obliterarse con mayor facilidad ${ }^{6}$. Los tapones mucosos son comunes y se visualizan con facilidad en la TC. El relleno de la vía aérea con mucus o pus o la inflamación peribronquiolar, crean opacidades centro-lobulillares en aspecto de "árbol en brote" 4 . A medida que la enfermedad progresa, aparecen bronquiectasias generalmente cilíndricas y en menor grado varicosas o saculares, que predominan inicialmente en los lóbulos superiores, probablemente debido a una menor excursión respiratoria y peor drenaje de secreciones en esas zonas. La impactación mucosa que se produce en los bronquios puede determinar atelectasias segmentarias y lobulares ${ }^{6}$. La alteración más común de la vía aérea en lactantes y niños con FQ comparado con controles sanos es el engrosamiento de la pared y la dilatación bronquial ${ }^{7}$.

La evaluación del diámetro de la vía aérea para el diagnóstico de bronquiectasias, junto a la importancia del patrón en mosaico ponen de manifiesto que el manejo del volumen pulmonar que se realice durante la adquisición de las imágenes, resulta vital para su adecuada interpretación. Si el paciente no puede colaborar con maniobras de apnea a capacidad pulmonar total, entonces con frecuencia se recurre a la intubación bajo anestesia, como ocurre con frecuencia en nuestro medio. Sin embargo, la técnica de TC bajo ventilación controlada sin intubación, permite adquirir imágenes a distintos volúmenes pulmonares en forma segura y confiable, utilizando ventilación con bolsa y mascarilla facial para hiperventilar a un niño sedado con hidrato de cloral, obteniendo imágenes durante la apnea refleja que produce este procedimiento ${ }^{8}$.

Por último, la correlación entre las alteraciones detectadas con TC no siempre guardan correlación con las pruebas de función pulmonar ${ }^{9}$. La presencia de bronquiectasias debido a FQ no deben contraindicar el ejercicio, toda vez que el desempeño en pruebas de ejercicio en estos pacientes no difiere con los obtenidos por pacientes con bronquiectasias de otra causa ${ }^{10}$.

\section{BIBLIOGRAFÍA}

1.- SÁNCHEZ I, PÉREZ M, BOZA M L, LEZANA V, VILA A, REPETTO G, et al. Consenso nacional de fibrosis quística. Rev Chil Pediatr 2001; 72: 356-80.

2.- MEHTA A. CFTR: More than just a chloride channel. Pediatr Pulmonol 2005; 39: 292-8.

3.- GIBSON R, BURNS J, RAMSEY B. Pathophysiology and management of pulmonary infections in cystic fibrosis. Am J Respir Crit Care Med 2003; 168: 91851.

4.- ROSSI U, OWENS C. The radiology of chronic lung disease in children. Arch Dis Child 2005; 90: 601-7.

5.- BRODY E. Thoracic manifestations of systemic diseases. En: Lucaya J, Strife J, ed. Pediatric Chest Imaging. Springer-Verlag 2002; 245-63.

6.- SIBTAIN N, PADLEY S. HRCT in small and large airways diseases. Eur Radiol 2004; 14, suppl 4: L31L43.

7.- LONG F, WILLIAMS R, CASTILE R. Structural airway abnormalities in infants and young children with cystic fibrosis. J Pediatr 2004; 144: 154-61.

8.- LONG F. Imaging evolution of airway disorders in children. Radiol Clin N Am 2005; 43: 371-89.

9.- BRODY A, KLEIN J, MOLINA P, QUAN J, BEAN J A, WILMOTT R W. High-resolution computed tomography in young patients with cystic fibrosis: distribution of abnormalities and correlation with pulmonary function tests. J Pediatr 2004; 145: 132-8.

10.- EDWARDS E, NARANG I, LI A, HANSELL D, ROSENTHAL M, BUSH A. HRCT lung abnormalities are not a surrogate for exercise limitation in bronchiectasis. Eur Respir J 2004; 24: 538-44. 